\title{
COMPARISON ANALYSIS OF SHUNT ACTIVE FilTER AND TRANSFORMERLESS PARALLEL HYBRID ACTIVE FILTER
}

\author{
Sakshi Bangia ${ }^{1}$, P.R.Sharma ${ }^{2}$ and Maneesha Garg $^{3}$ \\ ${ }^{1,2}$ Department of Electrical Engineering, YMCA University Of Science and \\ Technology, Faridabad \\ ${ }^{1}$ sakshibangia@gmail.com, ${ }^{2}$ prsharma1966@gmail.com \\ ${ }^{3}$ Department of Humanities and Applied Science, YMCA University Of \\ Science and Technology, Faridabad \\ Garg_maneesha@yahoo.com
}

\begin{abstract}
This research work presents the comparison analysis of Shunt Active Filter (SAF) with Parallel Hybrid Active Filter (PHAF). The performances of SAF and PHAF have been analyzed with PI controllers based on Synchronous Reference Frame theory. In each case, simulation is carried out for three phase unbalanced non liner load conditions. The advantages of the designed system and the proposed current reference calculation methods are verified by simulations using MATLAB Power system Toolbox.
\end{abstract}

\section{KEYWORDS}

Power quality, shunt active filter, transformer-less shunt hybrid active filter, Total Harmonic Distortion

\section{INTRODUCTION}

Harmonics are injected in source current due to the application of non-linear load. These harmonic currents influence the function of other equipment connected on the similar distribution feeder, including the harmonic producing loads. Among number of solutions conventionally passive filters offers a low cost solution. They generally offer high series impedance or low shunt impedance to block the particular harmonic content. However there are certain disadvantages like fixed compensation characteristics and resonances with the source impedance. Thus in orders to prevail over the demerits associated with traditional passive filters, Active Power Filters (APF) have been introduced in recent years. APF plays a vital role for controlling the amount of harmonic pollution present in a distribution system. They can be connected in series, shunt or combination of series and shunt with the supply impedance.

Typically shunt APF consists of a three phase voltage source inverter with capacitor on dc side. For large power applications, it is difficult to implement a low loss and a low cost PWM Jan Zizka (Eds) : CCSIT, SIPP, AISC, PDCTA - 2013

pp. 373-382, 2013. C CS \& IT-CSCP 2013

DOI : $10.5121 /$ csit.2013.3642 
converter. When this equipment is connected in shunt to the ac source impedance it is possible to improve the compensation characteristics of the passive filters in parallel connection [1], [2].This forms the transformerless Parallel Hybrid Active Filter The aim of PHAF is to mitigate the problems associated with SAF and passive filters and to complement and enhance their performance by adding active or passive components to their structure [3].Figure 1 shows the block diagram of transformerless parallel hybrid filter.

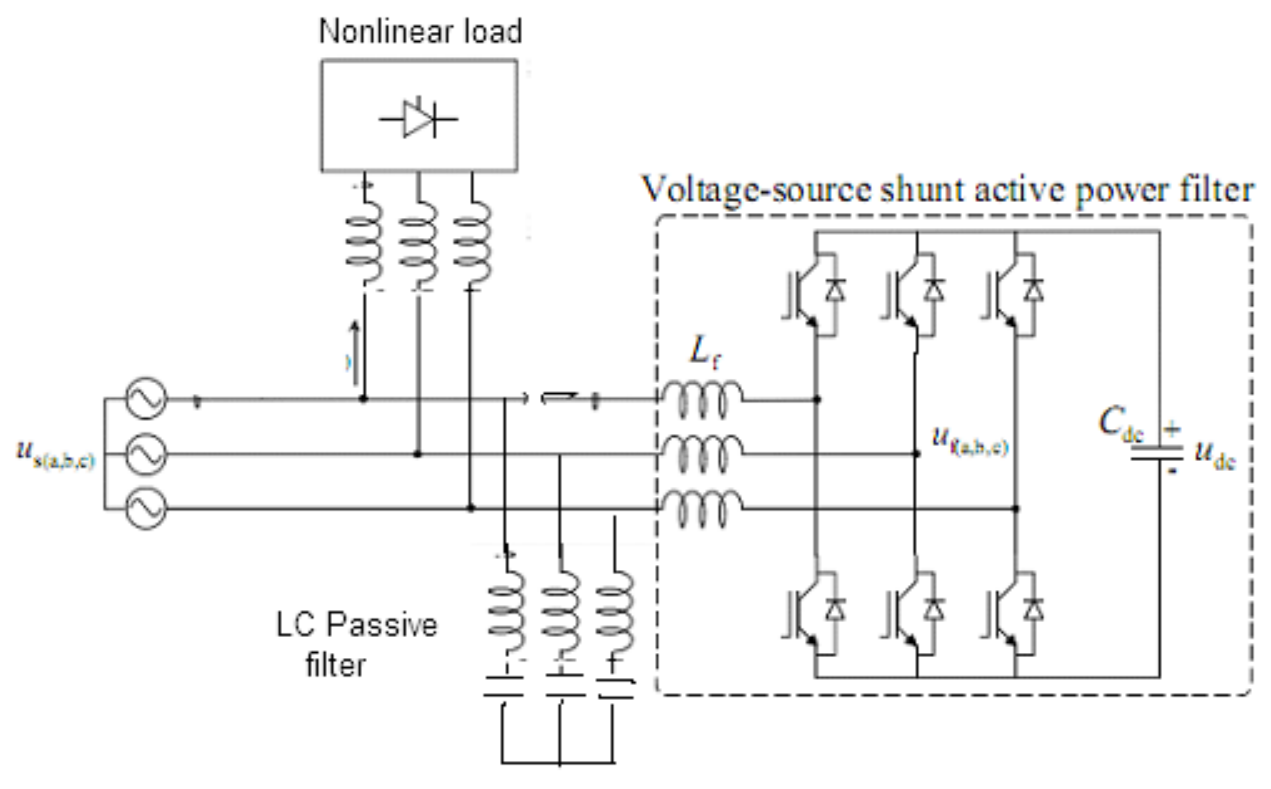

Figure 1. Block Diagram of Parallel Hybrid Active Filter

\section{PRINCIPLE OF OPERATION}

Hybrid active filters effectively mitigate the problems of a passive and an active filter and provide cost-effective harmonic compensation, particularly for high-power nonlinear loads [4].The parallel hybrid filter consists of three phase voltage source inverter with capacitor on the dc side connected in shunt with the tuned passive filter. Shunt passive filter is a series combination of a capacitor and a reactor tuned to a specific harmonic frequency. Since nonlinear load contributes the major contribution of harmonics in the source current mainly due to lower order harmonics thus tuned filter provides low impedance trap to harmonic. Remaining higher order harmonics only are to be filtered by shunt active filter; hence its power rating can be reduced The compensation of harmonics in the source current through enhancement of the compensation characteristics of the passive filters also eliminates the chances of resonance [5].

The performance of the PHAF depends on the computation of reference compensating signal. Among many control strategies mentioned for estimating the reference compensating current Instantaneous Reactive Power (IRP) theory $[6,7]$ and Synchronous Reference Frame (SRF) are mostly used. [8].These schemes employ the computation of the reference components through subtraction of positive sequence fundamental current component from the load/source current. These control strategies are very attractive for their simplicity and ease of implementation, but lack in providing adequate solution under extreme or severe condition of fault conditions in 
passive filter branch. SRF control technique using proportional integral (PI) type controller are is implemented to strength the currents of the filter to follow their reference values.

\section{SYSTEM CONFIGURATION}

A three phase parallel hybrid active filter is implemented for unbalance nonlinear load. The test system consists of shunt connected active filter with shunt passive LC elements tuned 5th harmonic frequency which the most prominent frequency is causing the distortion in source current. Passive filters are designed to result in minimum Root Mean Square (RMS) value of supply current at full load $[9,10]$. Proposal of Synchronous Reference Frame theory is included in [11].

\section{Design Parameters of Shunt ACtive Filter}

A shunt active filter consists of three phase, 6 pulse voltage source inverter. The line-line voltage is considered as $415 \mathrm{~V}$. The design for dc bus capacitor, dc bus voltage and ac inductor are as follows.

\subsection{Capacitor Voltage}

The minimum dc bus voltage should be greater than twice of the peak of the phase voltage of the system [13]. The dc bus voltage is calculated as

$$
V_{d c}=\frac{2 \sqrt{2}}{\sqrt{3}} \frac{V_{L-L}}{m}
$$

where, $\mathrm{m}$ is the modulation index $=1$ and is considered as 1 and VLL is the ac line voltage of three phase source.

\subsection{Bus Capacitor}

The value of dc bus capacitor $\left(\mathrm{C}_{\mathrm{dc}}\right)$ is given by

$$
\frac{1}{2} C_{d c}\left[\left(V_{d c}^{2}\right)-\left(V_{d c}^{2}\right)\right]=3 V(a I) t
$$

where, Vdc is the reference dc voltage and Vdc1 is the minimum voltage level of dc bus, a is the over loading factor taken as $1.2, \mathrm{~V}$ is the phase voltage, $\mathrm{I}$ is the phase current and $\mathrm{t}$ is time by which the dc bus voltage is to be recovered.

\subsection{AC Filter}

The ac inductance (Lf) depends on the current ripple $i_{\text {cr,p-p }}$, switching frequency $f_{s}$, dc bus voltage $\left(\mathrm{V}_{\mathrm{dc}}\right)$.Thus $\mathrm{Lf}$ is given as 


$$
\mathrm{L}_{\mathrm{f}}=\frac{\sqrt{3}}{12} \frac{m V_{d c}}{a f_{s} \boldsymbol{i}_{c r p-p}}
$$

where, $\mathrm{i}_{\text {crp-p }},=5 \%$

\section{Design Parameters of PASsive Filter}

The basic of shunt passive filter is to trap the tuned harmonic component in the source current using LC circuit. At resonance frequency inductive reactance is equal to that of capacitive reactance. Hence for single tuned filter, resonance frequency is given by

$$
f=\frac{1}{2 \pi \sqrt{L_{f} C_{f}}}
$$

Thus to design the size of capacitor, first step is to fixed the reactive power compensation .Hence capacitance can be calculated by

$$
X_{c}=\frac{V_{L-L}^{2}}{k V A R . f i l t e r}
$$

where $\mathrm{V}_{\mathrm{L}-\mathrm{L}}$ is line -line source voltage

$\mathrm{kVAR}$ is the fixed reactive power compensation

\section{Control Strategy}

The main function of the SRF control strategy is to provide high resistance at the fundamental frequency and also zero impedance is presented to harmonic current flowing in to the passive filter. [12].The control diagram is shown in Fig 2.

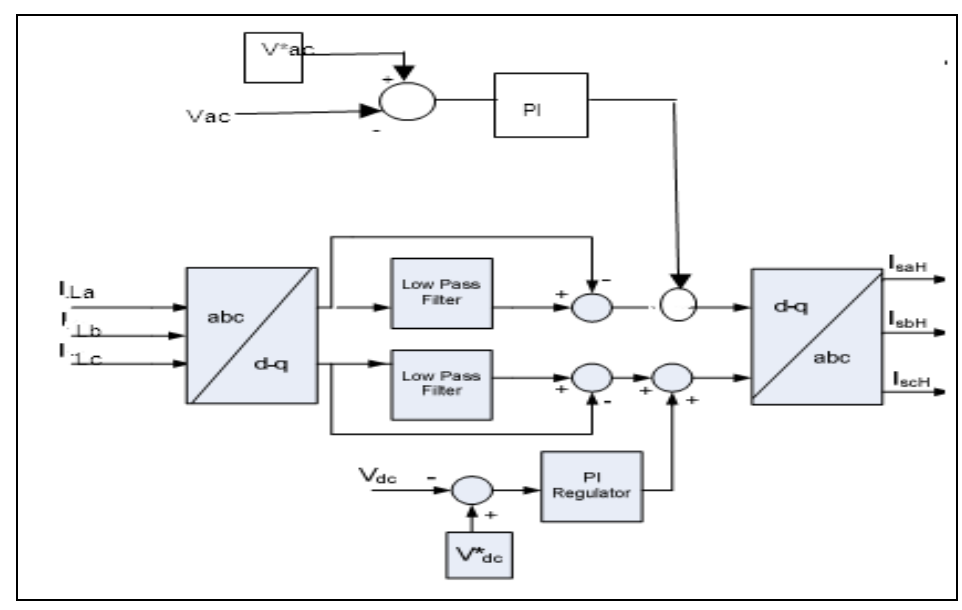

Fig 2 Synchronous Reference Frame Control Scheme 
In this three phase load current is transformed into d-q stationary reference frame using Parks Transformation. Using this fundamental component appears as DC quantities and all other harmonics are transformed as non-DC quantities. These quantities are not required hence these can be filter out using low pass filter. The extracted dc components and are transformed back into $\mathrm{a}-\mathrm{b}-\mathrm{c}$ coordinates to obtain the fundamental components of source currents. To compensate for the inverter losses PI controller is applied to regulate the DC bus voltage.

The output of PI controller at the dc bus voltage of active filter is considered as the current ( $\mathrm{il}_{\mathrm{oss}}$ ) for meeting its losses.

$$
i_{\text {loss }(n)}=i_{\text {loss }(n-1)}+k_{p d}\left(v_{d e(n)}-v_{d e(n-1)}\right)+k_{i d} v_{d e(n)}
$$

where, $v_{d e}-v_{d e(n-1)}$ is the error between the reference $\left(\mathrm{v}_{\mathrm{dc}}{ }^{*}\right)$ and sensed $\left(\mathrm{v}_{\mathrm{dc}}\right) \mathrm{dc}$

voltage at the nth sampling instant. $\mathrm{K}_{\mathrm{pd}}$ and $\mathrm{K}_{\mathrm{id}}$ are the proportional and the integral gains of the dc bus voltage PI controller.

The reference source current is therefore expressed as,

$i_{d}^{*}=i_{d d}+i_{\text {loss }}$

Similarly PI controller is used to regulate reactive power

$i_{q r(n)}=i_{q r s(n-1)}+k_{p q}\left(v_{t e(n)}-v_{t e(n-1)}\right)+k_{i q} v_{t e(n)}$

The reference supply quadrature axis current is as

$i_{q}^{*}=i_{q d}+i_{q r}$

where, $v_{\text {te }(n)}=v_{s}{ }^{*}-v_{(n)}$ denotes the error between reference $\left(\mathrm{v}_{\mathrm{s}}{ }^{*}\right)$ and actual $\left.\left(\mathrm{v}_{\mathrm{s}(\mathrm{n}}\right)\right)$ terminal voltage amplitudes at the $n$ sampling instant. $K_{p q}$ and $K_{i q}$ are the proportional and the integral gains of the PI controller.

\section{MATLAB IMPLEMENTATION}

A three phase transformerless hybrid active filter is implemented using MATLAB Power system Toolbox. Three phase input source voltage of $415 \mathrm{~V}, 50 \mathrm{~Hz}$ frequency with source resistance of $0.2 \mathrm{ohms}$ and inductance of $2 \mathrm{mH}$ is considered. A three phase unbalance nonlinear load drawing $5 \mathrm{~A}$ is considered for simulation. Shunt active filter is constituted of 6 pulse VSI with 2200 e- $6 \mathrm{~F}$ of capacitance attached to the DC side. A small-rated filter has been included to minimize the switching ripples at the inverter output. Passive elements of the filter are calculated using the mathematical relation s considering $50 \%$ of fixed reactive compensation. Table1 gives the detailed parameters of the system. 
Table 1. Detailed Parameters of the System.

\begin{tabular}{|l|l|}
\hline Parameters & Values \\
\hline Supply voltage & $415 \mathrm{~V}(\mathrm{~L}-\mathrm{L}), 50 \mathrm{~Hz}$ \\
\hline Loads: & $\begin{array}{l}\text { (i) Linear: phase a }=25 \Omega \\
\text { Phase } \mathrm{b}=10 \Omega \text { and } 80 \mathrm{mH} \\
\text { Phase } \mathrm{c}=10 \Omega \text { and } 80 \mathrm{mH} \\
\text { (ii) Nonlinear: Three phase } \\
\text { full bridge rectifier drawing } \\
15 \mathrm{~A}\end{array}$ \\
\hline $\begin{array}{l}\text { Shunt Active Filter: } \\
\text { Interfacing } \\
\text { Inductance }\end{array}$ & $\mathrm{L}_{\mathrm{f}}=5.5 \mathrm{mH}$ \\
\hline DC bus capacitance & $22000 \mathrm{e}-6 \mathrm{~F}$. \\
\hline $\begin{array}{l}\text { Referenced Dc } \\
\text { voltage }\end{array}$ & $750 \mathrm{~V}$ \\
\hline Tuned Passive Filter & $\mathrm{C}_{5}=129.4 \mathrm{e}-6 \mathrm{~F} ; \mathrm{L}_{5}=3.1 \mathrm{mH}$ \\
\hline
\end{tabular}

\section{RESUlTS AND DiSCUSSION}

The performance of the presented SRF control strategy is evaluated using by comparison of pure shunt active power filter and parallel hybrid power filter. The three phase unbalance nonlinear load considered here in the present system contains 5th harmonic content as the most prominent factor which causes the distortion in the source current. Hence the passive elements of the hybrid filter are tuned for the resonance frequency of $250 \mathrm{~Hz}$. The VA rating required for the inverter in the hybrid filter is much lesser than that required in a pure shunt active filter.

The VA rating required of the inverter in parallel hybrid power active filter is given by

VA rating $=\sqrt{3} \times \frac{V_{d c}}{\sqrt{2}} \times \frac{I_{F M A X}}{\sqrt{2}}$

Where $\mathrm{I}_{\mathrm{FMAX}} \cong 13 A$ is the maximum filter current.

Also the apparent power rating of nonlinear load is given by

VA rating $=3 \times V_{\text {Srms }} \times I_{\text {Lrms }}$

Where $V_{\text {Srms }}$ and $I_{\text {Lrms }}$ are the RMS value of source voltage taken as $415 \mathrm{~V}$ and load current taken as $38 \mathrm{~A}$.

The apparent ratio of the parallel hybrid filter and nonlinear load is greatly reduced by $16 \%$. Another factor which determines the validation of active filters is Total Harmonic Distortion (THD) is reduced from $14.74 \%$ to $2.65 \%$ for phase a. Table II shows the THD for all three phases for different types of filter. It can be seen from Fig 5 and Table III that parallel hybrid filter system is able to reduce the 5th harmonic of supply current to $1.68 \%$.The THD of the ac supply current reduces to $3.27 \%$ with pure shunt active power filters alone as the major component of the load current without any filter is composed of 5th harmonic. 
TABLE III Harmonic Current in Percentage of Fundamental Current

\begin{tabular}{|l|l|l|l|l|l|l|}
\hline & 5 th & 7 th & 11 th & 13 th & 17 th & 19 th \\
\hline Load current & 12.76 & 5.42 & 3.92 & 2.23 & 1.55 & 0.97 \\
\hline $\begin{array}{l}\text { Source current } \\
\text { with Passive Filter }\end{array}$ & 0.20 & 2.69 & 2.57 & 1.64 & 1.13 & 0.89 \\
\hline $\begin{array}{l}\text { Source current } \\
\text { with Pure Shunt } \\
\text { Active Filter }\end{array}$ & 1.83 & 0.54 & 0.64 & 0.65 & 0.83 & 0.05 \\
\hline $\begin{array}{l}\text { Source current } \\
\text { with Shunt Hybrid } \\
\text { Active Filter }\end{array}$ & 1.68 & 1.03 & 0.23 & 0.21 & 0.19 & 0.13 \\
\hline
\end{tabular}

Figure 3 shows the waveform of load current without filter. Fig 4 and 5 shows the waveform of source current with pure shunt active filter and parallel hybrid active filter respectively. These waveforms clearly illustrates that load current is very distorted that implies source current at this time without filtering is also very distorted. With the application of power filter source currents can be made sinusoidal .Clearly with the application of parallel hybrid active filter source current is less distorted and contains less harmonics content as compared to pure shunt active filter. Fig 6 shows the uncompensated and compensated reactive power using parallel hybrid active filter .Since the passive elements are tuned at fixed 50\% compensation, fig 6 clearly validates the passive parameters of hybrid filter. Fig7 demonstrates the source voltage, source current, load voltage, load current, DC bus voltage, and filter current for parallel hybrid active filter.

TABLE II THD For Different Phases (in percentage)

\begin{tabular}{|l|l|l|l|}
\hline \multicolumn{1}{|c|}{ Phase $\rightarrow$} & Phase a & $\begin{array}{l}\text { Phas } \\
\text { e b }\end{array}$ & $\begin{array}{l}\text { Phase } \\
\text { c }\end{array}$ \\
\hline $\begin{array}{l}\text { Load current } \\
\text { without filter }\end{array}$ & 14.74 & 16.27 & 19.66 \\
\hline $\begin{array}{l}\text { Pure shunt active } \\
\text { filter }\end{array}$ & 3.27 & 4.58 & 3.75 \\
\hline Parallel hybrid filter & 2.65 & 3.15 & 2.64 \\
\hline
\end{tabular}




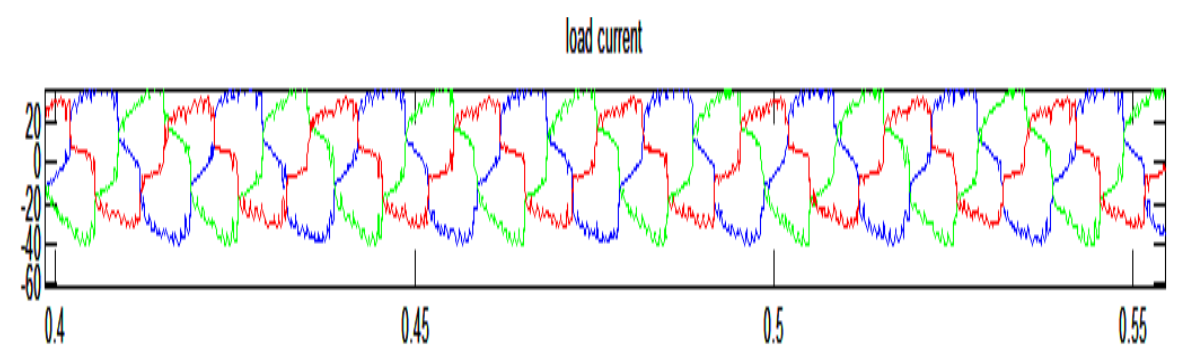

Figure 3 Load current

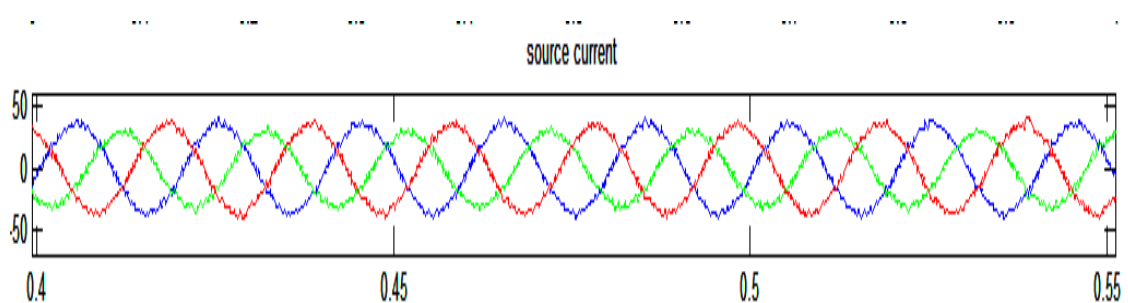

Figure 4 Source Current with Pure Active Filter

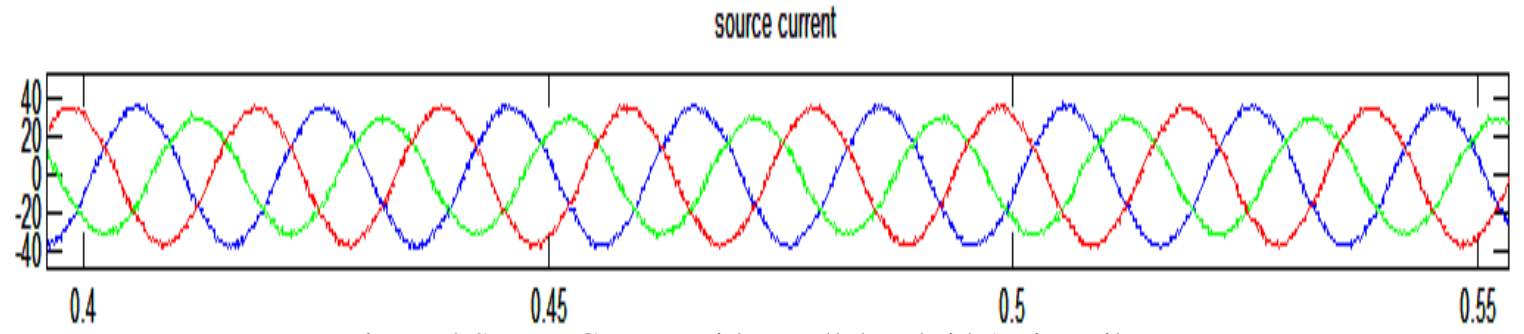

Figure 4 Source Current with Parallel Hybrid Active Filter

LOAD REACTIVE POWER
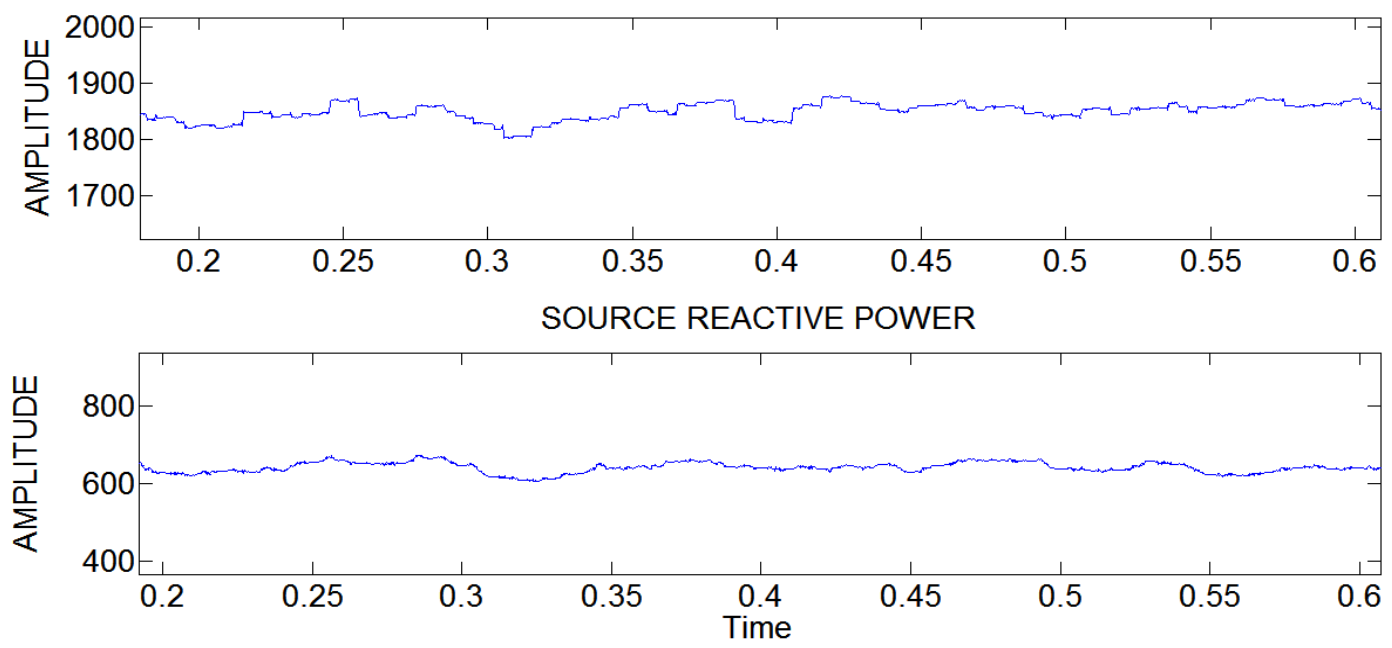

Figure 6 Load Reactive Power and Source Reactive power using parallel Hybrid Active Filter 

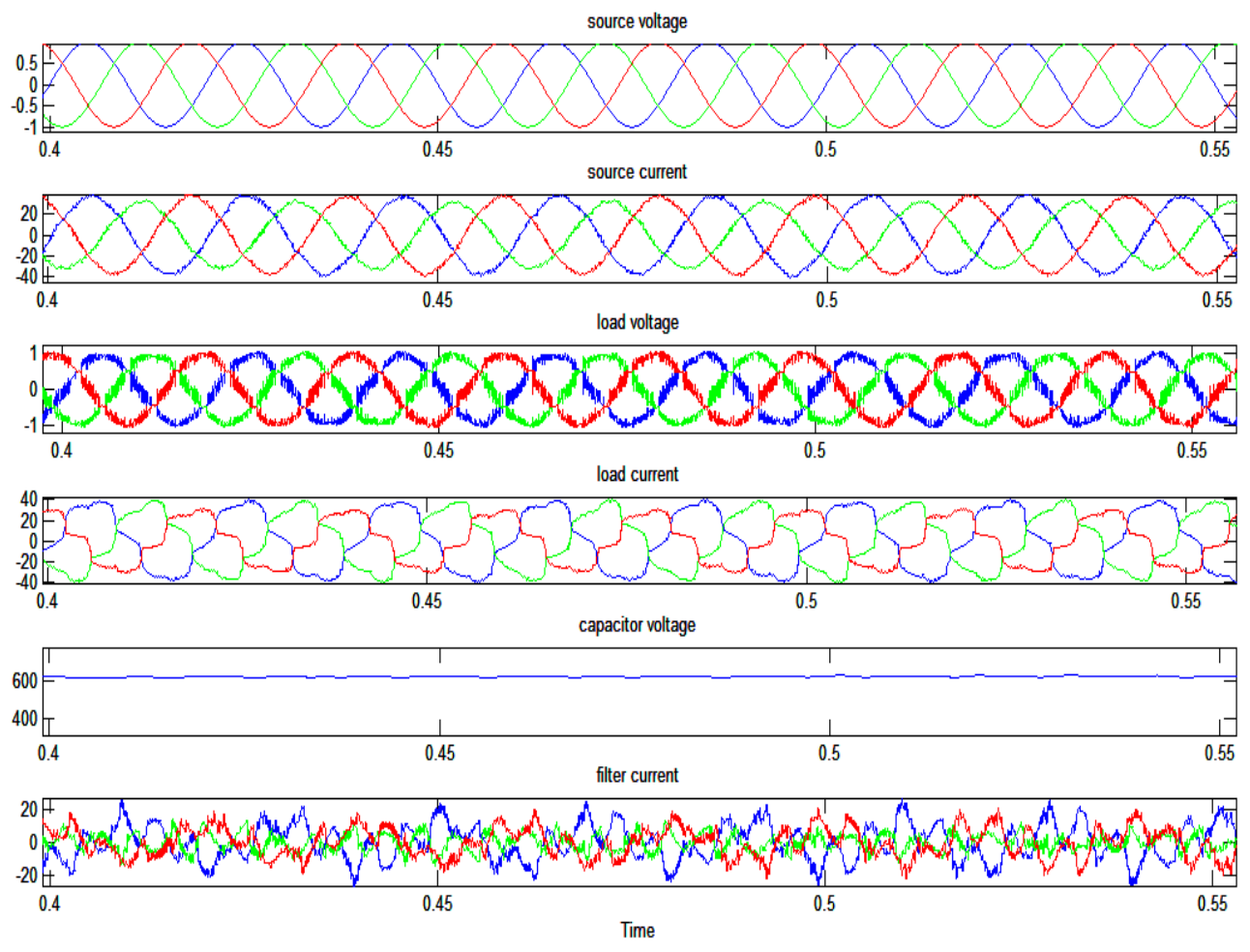

Figure 7 Source Voltage, Source Current, Load Voltage, Load Current, DC Bus Voltage, Filter Current.

\section{Conclusions}

In this work, concept of transformerless parallel hybrid active filter is defined and verified by MATLAB simulation. Simulation results verify that presented method has good performance in the elimination of selective harmonic content and Total Harmonic Distortion. It has much better dynamic response with less rating compared with the pure shunt active filter.

\section{REFERENCES}

[1] B. Singh, K. Al-Haddad, and A. Chandra, "A review of active filters for power quality improvement," IEEE Trans. Ind. Electron., vol. 46, no. 5, pp. 960-971, Oct. 1999.

[2] J.W. Dixon, G. Venegas, and L. A.Moran, "A series active power filter based on a sinusoidal currentcontrolled voltage-source inverter," IEEE Trans. Ind. Electron., vol. 44, no. 5, pp. 612-620, Oct. 1997.

[3] Bhattacharya,Divan,"Synchronous Frame based controller implementation for a hybrid series active filter,Confeence record of IEEE Industry Apllications Conference Vol, 3,pp. 2531-2540 October 1995.

[4] S. Srianthumrong and H. Akagi, "A medium-voltage transformerless AC/DC power conversion system consisting of a diode rectifier and a shunt hybrid filter," IEEE Trans. Ind. Appl., vol. 39, no. 3, pp. 874-882, May/Jun. 2003.

[5] H. Fujita, T. Yamasaki and H. Akagi, "A hybrid active filter for damping of harmonic resonance in industrial power systems," IEEE Trans. on Power Electronics, vol. 15, no. 2, pp. 215-222, March 2000 . 
[6] H. Fujita, H. Akagi, "A Practical Approach to Harmonic Compensation in Power Systems-Series Connection of Passive, Active Filters," IEEE Trans. on Ind.. Appl., vol.27, no.6, pp. 1020-1025, Nov./Dec. 1991.

[7] F.B. Libano, J.A.Cobos, J. Uceda, "Simplified control strategy for Hybrid Active Filters", IEEE PESC Record, 1 997, pp 1102-1108.

[8] P.T. Cheng, S. Bhattacharya and D. Divan, "Experimental Verification of Dominant Harmonic Active Filter for High Power Applications",IEEE Trans. on Ind. Appl., vol. 36, pp.567-577, March/April, 2000.

[9] IEEE Guide for Application and Specification of Harmonic Filters IEEE Std 1531-2003.

[10] V, Verma, S. Shanker, B. Singh, A. Chandra, and Kamal Al- Haddad, "Genetic Algorithm Based Design of Passive Filters for Offshore Applications," Proc. ofIEEE PCIC '04, 2004, pp 55-62.

[11] S. Bhattacharya, D. Divan and B. Banerjee, "Synchronous frame harmonic isolator using active series filter," EPE-Firenze, Vol. 3, pp. 30-35, 1991.

[12] V, Verma, S. Shanker, B. Singh,'Design and Implemention of Current Controlled Parallel Hybrid Power Filter.

[13] B.N.Singh, P.Rastgoufard, B.Singh, A.Chandra and K.Al.Haddad, "Design,simulation and implementation of three pole/ four pole topologies for active filters," IEE Eletr. Power Appl., vol. 151, no. 4, pp. 467-476, July 2004.

\section{Authors}

Sakshi Bangia received the B.Tech degree in Instrumentation and Control from MDU Rohtak and M.Tech degree in Electrical Engg. from YMCA UST in 2004 and 2006, respectively. She is pursuing Ph.D in Power Quality from Maharishi Dayanand University, India. Presently she is working as Assistant Professor in Electrical Engineering Department at YMCA UST Faridabad.

Dr. P.R.Sharma was born in 1966 in India. He is currently working as Chairman of the Department in Electrical Engg. in YMCA University Of Science and Technology, Faridabad. He received his B.E Electrical Engineering in 1988 from Punjab University Chandigarh, M.Tech in Electrical Engineering (Power System) from Regional Engineering College Kurukshetra in 1990 and $\mathrm{Ph} . \mathrm{D}$ from M.D.University Rohtak in 2005. He started his carrier from industry. He has vast experience in the industry and teaching. His area of interest is Optimal location and coordinated control of FACTS devices , power system stability and control

Dr. Maneesha Garg did her Ph.D(Physics) in 2002 from Kurukshetra University, India. After that she worked as Research Associate granted by CSIR, in NIT Kurukshetra for 4 years. She has 18 publications in national, international journals and more than 30 papers in conferences to her credit. Presently she is working as Assistant Professor in Humanities and Applied Science Department, YMCA UST, Faridabad and guiding 4 scholars for their research work.
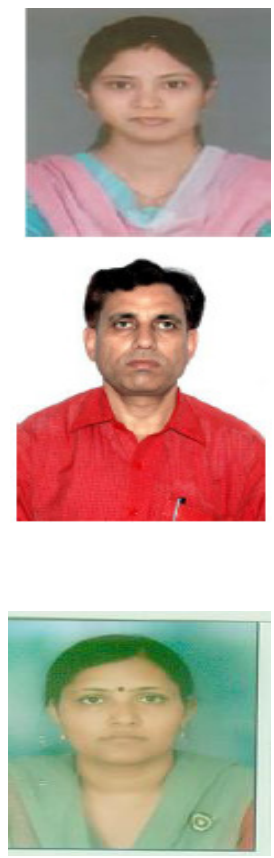